\title{
Simple Risk Score to Predict Survival in Acute Decompensated Heart Failure
}

\author{
$-\mathrm{A}_{2} \mathrm{~B}$ Score -
}

\author{
Yasuki Nakada, MD, PhD; Rika Kawakami, MD, PhD; Shouji Matsushima, MD, PhD; \\ Tomomi Ide, MD, PhD; Koshiro Kanaoka, MD; Tomoya Ueda, MD, PhD; \\ Satomi Ishihara, MD; Taku Nishida, MD, PhD; Kenji Onoue, MD, PhD; \\ Tsunenari Soeda, MD, PhD; Satoshi Okayama, MD, PhD; Makoto Watanabe, MD, PhD; \\ Hiroyuki Okura, MD, PhD; Miyuki Tsuchihashi-Makaya, PhD; \\ Hiroyuki Tsutsui, MD, PhD; Yoshihiko Saito, MD, PhD
}

\begin{abstract}
Background: Prognosis after acute decompensated heart failure (ADHF) is poor. An appropriate risk score that would allow for improved care and treatment of ADHF patients after discharge, however, is lacking.

Methods and Results: We used 2 HF cohorts, the NARA-HF study and JCARE-CARD, as derivation and validation cohorts, respectively. The primary endpoint was all-cause death during the 2-year follow-up, excluding in-hospital death. Age, hemoglobin $(\mathrm{Hb})$, and brain natriuretic peptide (BNP) at discharge were identified as independent risk factors. We determined 3 categorizations on the basis of these parameters, termed $\mathrm{A}_{2} \mathrm{~B}$ score: age ( $<65$ years, $0 ; 65-74$ years, $1 ; \geq 75$ years, 2), anemia $(\mathrm{Hb}<10 \mathrm{~g} / \mathrm{dL}, 2$; $10-11.9 \mathrm{~g} / \mathrm{dL}, 1 ; \geq 12 \mathrm{~g} / \mathrm{dL}, 0)$ and BNP (<200 pg/mL, 0; 200-499 pg/mL, $1 ; \geq 500 \mathrm{pg} / \mathrm{mL}, 2)$. We divided patients into 4 groups according to $\mathrm{A}_{2} \mathrm{~B}$ score (extremely low, 0; low, 1-2; medium, 3-4; high, 5-6). For the extremely low-risk group, the 2-year survival rate was $97.8 \%$, compared with $84.5 \%, 66.1 \%$, and $45.2 \%$ for the low-, medium-, and high-risk groups, respectively. Using the JCARE-CARD as a validation model, for the extremely low-risk group, the 2 -year survival was $95.4 \%$, compared with $90.2 \%, 75.0 \%$, and $55.6 \%$ for the low-, medium-, and high-risk groups, respectively.
\end{abstract}

Conclusions: The user-friendly $A_{2} B$ score is useful for estimating survival rate in ADHF patients at discharge.

Key Words: Acute decompensated heart failure; Outcome; Risk score

$\mathbf{T}$ he prognosis after acute decompensated heart failure (ADHF) is poor. Appropriate management strategies for ADHF vary according to age and survival rate in the aging society. To provide better care and treatment for patients with ADHF after discharge, it is necessary to predict mid-term outcome. Although some risk models exist for patients with chronic heart failure (CHF), ${ }^{1-6}$ it is unclear whether these scores can be directly applied to patients with ADHF. With the use of numerous parameters, such as those in The Meta-analysis Global Group in Chronic Heart Failure (MAGGIC) score or The Eplerenone in Mild Patients Hospitalization and Survival Study in Heart Failure trial (EMPHASIS-HF) risk score, more accurate risk assessment is possible, but these scores cannot be calculated rapidly without a computer.,5 In this study, we designed a more fundamental and a simpler score system for patients with ADHF.

\section{Methods}

\section{Study Design and Patients}

The present study used 2 HF cohorts, the Nara registry and analyses for heart failure (NARA-HF) 3 study and the Japanese Cardiac Registry of Heart Failure in Cardiology (JCARE-CARD). The NARA-HF 3 study was used as a derivation model, and the JCARE-CARD was used as a validation cohort.

The NARA-HF 3 study recruited 1,074 consecutive patients following emergency admission for ADHF between January 2007 and December 2016, as described previously. ${ }^{7,8}$ Diagnosis of HF was based on the Framingham study criteria. ${ }^{9}$ Patients with acute myocardial infarction, acute

Received October 9, 2018; revised manuscript received December 26, 2018; accepted January 27, 2019; J-STAGE Advance Publication released online March 7, 2019 Time for primary review: 28 days

Department of Cardiovascular Medicine, Nara Medical University, Kashihara (Y.N., R.K., K.K., T.U., S.I., T.N., K.O., T.S., S.O., M.W., H.O., Y.S.); Department of Cardiovascular Medicine, Graduate School of Medical Sciences, Kyushu University, Fukuoka (S.M., T.I., H.T.); and School of Nursing, Kitasato University, Tokyo (M.T.-M.), Japan

Mailing address: Yoshihiko Saito, MD, PhD, Department of Cardiovascular Medicine, Nara Medical University, 840 Shijo-cho, Kashihara 634-0813, Japan. E-mail: saitonaramed@gmail.com

ISSN-1346-9843 All rights are reserved to the Japanese Circulation Society. For permissions, please e-mail: cj@j-circ.or.jp 


\begin{tabular}{|c|c|c|}
\hline & $\begin{array}{c}\text { NARA-HF7,8 } \\
\text { (derivation), } \mathrm{n}=739\end{array}$ & $\begin{array}{l}\text { JCARE-CARD }{ }^{10,11} \\
\text { (validation), } \mathrm{n}=542\end{array}$ \\
\hline \multicolumn{3}{|l|}{ Demographics } \\
\hline Age (years) & $73.5 \pm 11.9$ & $69.3 \pm 13.7$ \\
\hline Gender (male) & 57.6 & 58.9 \\
\hline $\mathrm{BMI}\left(\mathrm{kg} / \mathrm{m}^{2}\right)$ & $23.6 \pm 9.6$ & $22.2 \pm 3.9$ \\
\hline \multicolumn{3}{|l|}{ Vital sign on admission } \\
\hline Heart rate (beats/min) & $96.8 \pm 27.1$ & $89.5 \pm 24.3$ \\
\hline $\mathrm{SBP}(\mathrm{mmHg})$ & $146.1 \pm 36.3$ & $134.4 \pm 31.4$ \\
\hline $\mathrm{DBP}(\mathrm{mmHg})$ & $83.5 \pm 23.7$ & $74.8 \pm 18.5$ \\
\hline \multicolumn{3}{|c|}{ Echocardiography parameters } \\
\hline LVDd (mm) & $54.0 \pm 9.6$ & $56.5 \pm 10.9$ \\
\hline LVDs (mm) & $41.3 \pm 11.7$ & $45.5 \pm 12.6$ \\
\hline LVEF (\%) & $45.3 \pm 16.6$ & $39.7 \pm 17.3$ \\
\hline \multicolumn{3}{|c|}{ Laboratory data at discharge } \\
\hline $\mathrm{Hb}(\mathrm{g} / \mathrm{dL})$ & $11.4 \pm 2.1$ & $12.2 \pm 2.4$ \\
\hline eGFR $\left(\mathrm{mL} / \mathrm{min} / 1.73 \mathrm{~m}^{2}\right)$ & $41.8 \pm 24.7$ & $51.2 \pm 24.8$ \\
\hline $\mathrm{BNP}(\mathrm{pg} / \mathrm{mL})$ & $267(138-543)$ & 237 (108-479) \\
\hline \multicolumn{3}{|l|}{ Medication at discharge } \\
\hline$\beta$-blockers & 61.2 & 57.4 \\
\hline ACEI/ARB & 89.7 & 81.9 \\
\hline Diuretics & 81.3 & 86.3 \\
\hline
\end{tabular}

Data given as mean \pm SD, median (IQR) or \%. ACEI, angiotensin-converting enzyme inhibitor; ARB, angiotensin II receptor blocker; BMI, body mass index; BNP, brain natriuretic peptide; DBP, diastolic blood pressure; eGFR, estimated glomerular filtration rate; Hb, hemoglobin; JCARE-CARD, Japanese Cardiac Registry of Heart Failure in Cardiology; LVDd, left ventricular end-diastolic dimension; LVDs, left ventricular end-systolic dimension; LVEF, left ventricular ejection fraction; NARA-HF, Nara registry and analyses for heart failure; SBP, systolic blood pressure.

myocarditis, or acute HF with acute pulmonary embolism were excluded. In this study, we included HF patients with temporal renal displacement therapy. Forty-one patients received treatment by continuous hemodiafiltration or the extracorporeal ultrafiltration method, 13 of whom had been previously treated with hemodialysis. Of the 1,074 enrolled patients, we excluded 45 who died during the current hospitalization, 24 who were lost to follow-up, 146 who were in the 2-year follow-up period, and 120 with missing discharge data. Thus, we analyzed 739 patients with ADHF.

The details of the JCARE-CARD have been described previously.10,11 Of 2,675 enrolled patients, we analyzed 542 patients who had discharge data and 2-year follow-up data (Supplementary Figure 1A).

The present study was approved by the Nara Medical University and Kyushu University Institutional Ethics Committee and was performed in accordance with the 1975 Declaration of Helsinki guidelines for clinical research protocols. Informed consent was obtained from all patients.

\section{Outcome}

The primary endpoint was all-cause death during 2-year follow-up, excluding in-hospital death. The status of all patients was surveyed and information on outcome was obtained from patient medical records and the participating cardiologists. When this information was unavailable in the medical records, clinicians telephoned the patients or their families to collect these data.

\section{Laboratory Parameters}

Discharge data were used to assess laboratory parameters including hemoglobin $(\mathrm{Hb})$, estimated glomerular filtration rate (eGFR), and plasma BNP. eGFR was calculated according to the previously published equation for Japanese persons: $194 \times$ serum creatinine ${ }^{-1.094} \times$ age $^{-0.287} \times(0.739$ for women). ${ }^{12}$

\section{Echocardiography}

Ultrasound was performed using the iE33 (Philips, Amsterdam, The Netherlands), Vivid E9 (GE Healthcare, Chicago, IL, USA), and Acuson Sequoia (Siemens, Berlin, Germany) systems. Left ventricular ejection fraction (LVEF) was calculated via the modified Simpson's method. Left ventricular (LV) end-diastolic diameter and LV end-systolic diameter were measured on M-mode echocardiography.

\section{Statistical Analysis}

Normally distributed data are presented as mean \pm SD and non-normally distributed data as median (IQR). Multivariable Cox proportional hazards modeling was used to identify strong independent baseline prognostic variables for the primary outcome. To simplify the risk score, we assigned integer points to each prognostic factor based on the log hazard ratio estimates. The total risk score for each patient was calculated by summing the points across all chosen prognostic variables. Cumulative event-free rates during follow-up were assessed using the Kaplan-Meier method. The area under the receiver operating characteristic (ROC) curve (AUC) was used to examine the discrimination of the models. The integrated discrimination improvement and the net reclassification index were calculated to assess improvement between models. Calibration of the final model was tested using the Grønnesby-Borgan goodness- 
Table 2. Predictors of Survival Using the NARA-HF Study Data7,8

\begin{tabular}{lcrrr} 
& $\begin{array}{c}\text { Univariate HR } \\
\mathbf{( 9 5 \% ~ C l )}\end{array}$ & $\begin{array}{c}\text { P-value } \\
\text { Age (per 10 years) }\end{array}$ & $\begin{array}{c}\text { Multivariate HR } \\
\mathbf{( 9 5 \%} \mathbf{~ C l )}\end{array}$ & $\begin{array}{c}\text { P-value } \\
\text { Male }\end{array}$ \\
BMI & $1.542(1.355-1.764)$ & $<0.0001$ & $1.533(1.280-1.851)$ & $<0.0001$ \\
SBP (per 10-mmHg increase) & $1.278(0.984-1.670)$ & 0.0662 & $1.330(0.940-1.892)$ & 0.1094 \\
LVEF & $0.999(0.973-1.015)$ & 0.9098 & $1.012(0.997-1.020)$ & 0.1038 \\
Hb & $0.916(0.849-0.987)$ & 0.0204 & $0.967(0.869-1.074)$ & 0.5367 \\
eGFR (per 10-mL/min/1.73 m ${ }^{2}$ increase) & $1.000(0.992-1.008)$ & 0.9840 & $0.998(0.987-1.009)$ & 0.6969 \\
BNP (per 100-pg/mL increase) & $0.804(0.749-0.861)$ & $<0.0001$ & $0.846(0.765-0.935)$ & 0.0009 \\
\hline
\end{tabular}

$\mathrm{Cl}$, confidence interval; $\mathrm{HR}$, hazard ratio. Other abbreviations as in Table 1.

\begin{tabular}{|c|c|c|c|c|c|c|}
\hline Biomarker & $\begin{array}{c}\text { C-statistic } \\
(95 \% \mathrm{Cl})\end{array}$ & P-value & $\begin{array}{c}\text { IDI } \\
(95 \% \mathrm{Cl})\end{array}$ & P-value & $\begin{array}{c}\text { NRI } \\
(95 \% \mathrm{Cl})\end{array}$ & P-value \\
\hline Group 1 (Age) & $0.655(0.613-0.697)$ & & & & & \\
\hline Group $2(\mathrm{Hb})$ & $0.647(0.605-0.688)$ & & & & & \\
\hline Group 3 (BNP) & $0.657(0.615-0.700)$ & & & & & \\
\hline Group $4(\mathrm{Age}+\mathrm{Hb})$ & $0.688(0.647-0.729)$ & & & & & \\
\hline Group 5 (Age+BNP) & $0.690(0.649-0.731)$ & & & & & \\
\hline Group $6(\mathrm{Hb}+\mathrm{BNP})$ & $0.677(0.636-0.718)$ & & & & & \\
\hline Group $7(\mathrm{Age}+\mathrm{Hb}+\mathrm{BNP})$ & $0.711(0.671-0.751)$ & & & & & \\
\hline Group 7 vs. Group 1 & & $<0.0001$ & $0.058(0.052-0.069)$ & $<0.0001$ & $0.480(0.400-0.559)$ & $<0.0001$ \\
\hline Group 7 vs. Group 2 & & 0.0004 & $0.062(0.053-0.071)$ & $<0.0001$ & $0.500(0.421-0.580)$ & $<0.0001$ \\
\hline Group 7 vs. Group 3 & & 0.0310 & $0.079(0.069-0.090)$ & $<0.0001$ & $0.502(0.423-0.581)$ & $<0.0001$ \\
\hline Group 7 vs. Group 4 & & 0.0010 & $0.026(0.020-0.033)$ & 0.0004 & $0.364(0.285-0.443)$ & $<0.0001$ \\
\hline Group 7 vs. Group 5 & & 0.0519 & $0.023(0.017-0.029)$ & 0.0001 & $0.306(0.227-0.385)$ & 0.0001 \\
\hline Group 7 vs. Group 6 & & 0.0373 & $0.042(0.035-0.050)$ & $<0.0001$ & $0.410(0.331-0.489)$ & $<0.0001$ \\
\hline
\end{tabular}

$\mathrm{BNP}$, brain natriuretic peptide; $\mathrm{Hb}$, hemoglobin; IDI, integrated discrimination improvement; $\mathrm{NRI}$, net reclassification improvement.

\begin{tabular}{|c|c|c|c|}
\hline Age (years) & HR $(95 \% \mathrm{Cl})$ & $\begin{array}{l}\text { P-value } \\
<0.0001\end{array}$ & Score \\
\hline$<65$ & Reference group & & 0 \\
\hline $65-74$ & $1.43(0.88-2.40)$ & & +1 \\
\hline$\geq 75$ & $2.38(1.57-3.76)$ & & +2 \\
\hline $\mathrm{Hb}(\mathrm{g} / \mathrm{dL})$ & & $<0.0001$ & \\
\hline$\geq 12$ & Reference group & & 0 \\
\hline $10-11.9$ & $1.76(1.24-2.54)$ & & +1 \\
\hline$<10$ & $2.32(1.63-3.37)$ & & +2 \\
\hline BNP (pg/mL) & & $<0.0001$ & \\
\hline$<200$ & Reference group & & 0 \\
\hline $200-499$ & $1.39(0.98-1.96)$ & & +1 \\
\hline$\geq 500+$ & $2.28(1.66-3.15)$ & & +2 \\
\hline
\end{tabular}

$\mathrm{A}_{2} \mathrm{~B}$ : age, $\mathrm{Hb}$ and $\mathrm{BNP}$. Other abbreviations as in Table 3.

of-fit statistic. $\mathrm{P}<0.05$ was considered statistically significant. JMP for Windows version 13 (SAS Institute, Cary, NC, USA) and STATA (Version 14, Stata Corp, College Station, TX, USA) were used for statistical analysis.

\section{Results}

\section{Baseline Characteristics}

In the NARA-HF 3 study, the mean age of the 739 patients was $74 \pm 12$ years and the proportion of male patients was $58 \%$ (Table 1). Mean LVEF was $45.3 \pm 16.6 \%$ and the prescription rate of $\beta$-blockers and renin-angiotensin system inhibitors at discharge was $61.2 \%$ and $89.7 \%$, respectively. Baseline characteristics of all patients included in the NARA-HF study are listed in Supplementary Table.

\section{Calculation of $A_{2} B$ Score}

There were 8 representative baseline variables available 

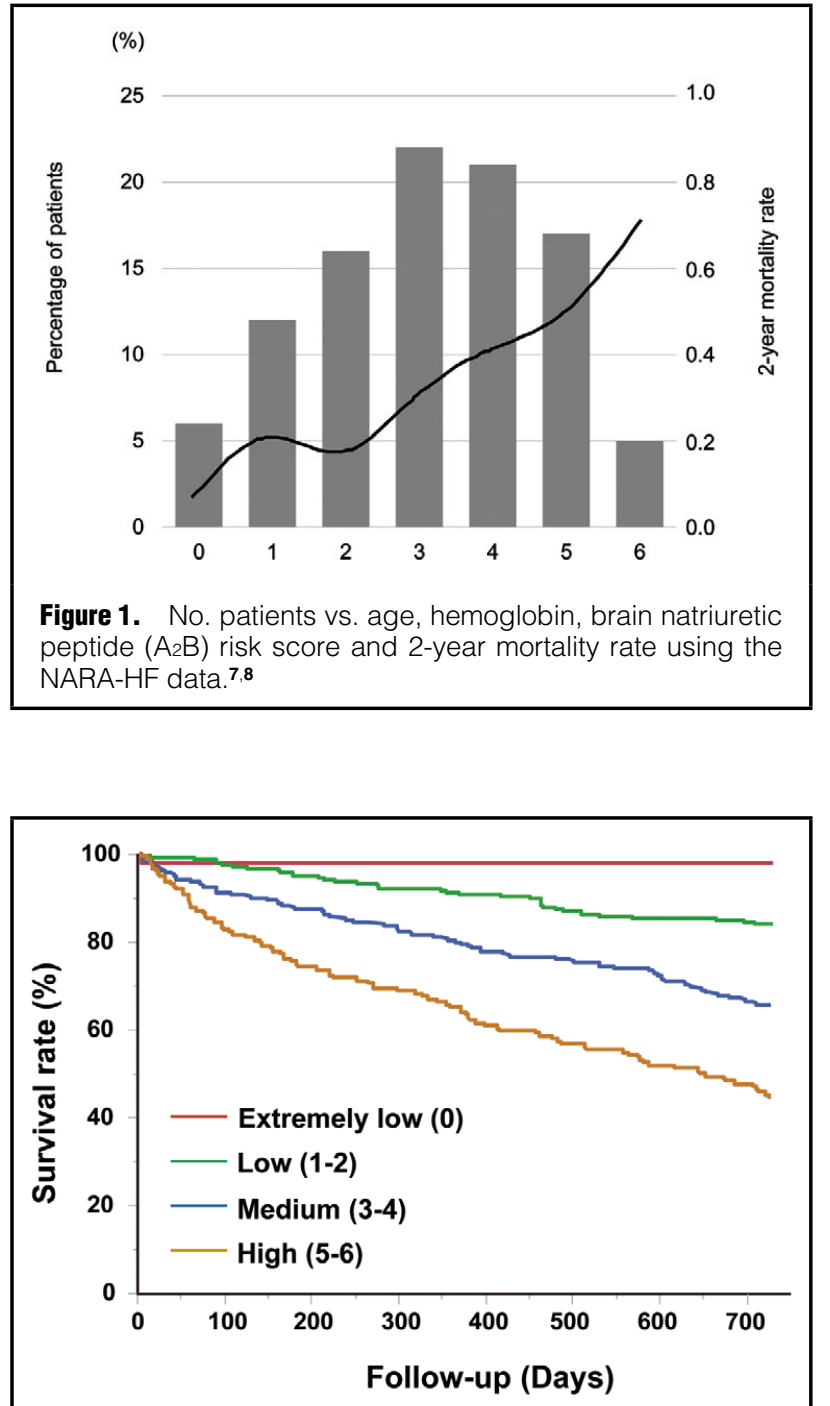

Figure 2. Kaplan-Meier event-free survival curves for 2-year all-cause death according to age, hemoglobin, brain natriuretic peptide $\left(A_{2} B\right)$ score using the NARA-HF data. ${ }^{7.8}$ Red line, extremely low risk, score $0, n=45$; green line, low risk, score $1-2, n=206$; blue line, medium risk, score $3-4, n=322$; brown line, high risk, score 5-6, $n=166$.

for inclusion in prognostic models (Table 2). Age, $\mathrm{Hb}$, and plasma BNP at discharge were found to be strong independent risk factors for the primary outcome in the multivariable Cox proportional hazards model. The risk of the primary outcome was found to increase with older age, lower $\mathrm{Hb}$, and higher plasma BNP.

To create the new $\mathrm{HF}$ risk score, termed the $\mathrm{A}_{2} \mathrm{~B}$ score, we included these 3 independent risk factors: age, anemia, and BNP. As shown in Table 3, the predictive values of all-cause mortality were compared between group 1 (age alone), group 2 (Hb alone), group 3 (BNP alone), group 4 $($ age $+\mathrm{Hb})$, group $5($ age $+\mathrm{BNP})$, group $6(\mathrm{Hb}+\mathrm{BNP})$, and group 7 (age $+\mathrm{Hb}+\mathrm{BNP})$. On $\mathrm{C}$-statistic analysis group 7 had a significantly improved discriminatory ability for all-cause mortality compared with groups $1-4$ and group 6 $(\mathrm{P}<0.05)$. Group 7 also had improved integrated discrimination and category-free net reclassification compared with

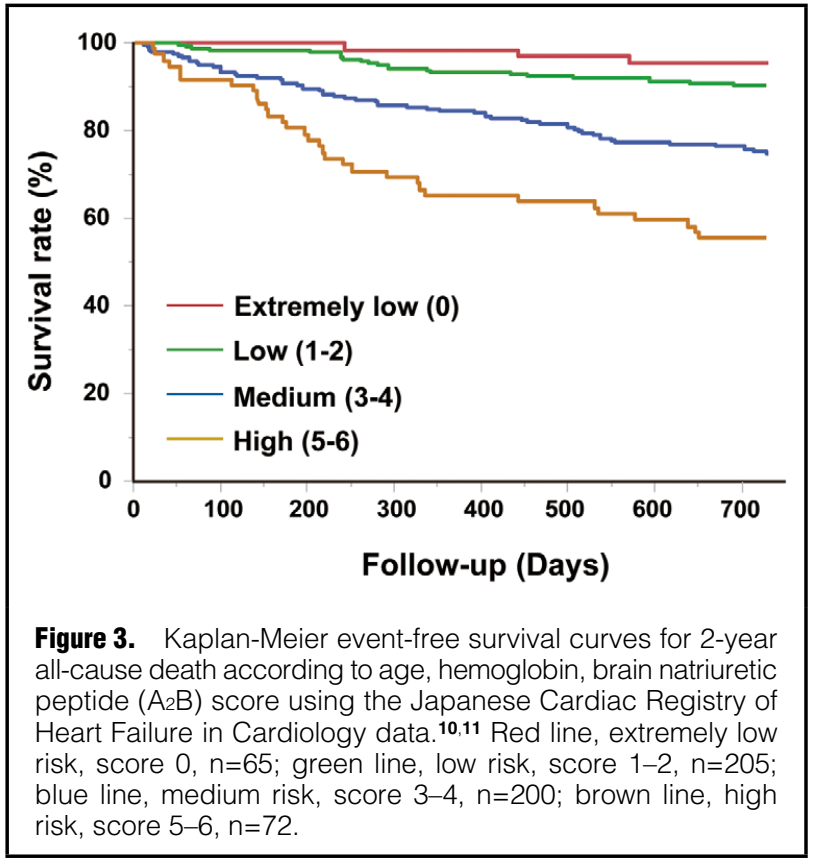

the other 6 groups $(\mathrm{P}<0.001)$.

The $\mathrm{A}_{2} \mathrm{~B}$ score is calculated as follows. For age, $\mathrm{Hb}$, and plasma BNP discharge, we determined 3 level categorizations (Table 4). Two points are added for age $\geq 75$ years, $\mathrm{Hb}<10 \mathrm{~g} / \mathrm{dL}$, or plasma $\mathrm{BNP} \geq 500 \mathrm{pg} / \mathrm{mL} ; 1$ point is added for age 65-74 years, $\mathrm{Hb} 10-11.9 \mathrm{~g} / \mathrm{dL}$, or plasma BNP $200-499 \mathrm{pg} / \mathrm{mL}$. The final model showed a good fit on Grønnesby-Borgan test $(\mathrm{P}=0.1012)$. The distribution of overall risk score across all patients in the NARA-HF study is shown in Figure 1, ranging from 0 to 6 points, with a median of 3 . We divided patients into 4 risk groups according to $\mathrm{A}_{2} \mathrm{~B}$ score: extremely low risk, 0; low risk, 1-2; medium risk, 3-4; and high risk, 5-6.

\section{$A_{2} B$ Score and All-Cause Death}

As a derivation model, we assessed the NARA-HF 3 study. On Kaplan-Meier analysis, in the extremely low-risk group almost all patients survived, whereas approximately one-half of patients in the high-risk group died (log-rank $\mathrm{P}<0.0001$; Figure 2). For the extremely low-risk group, the 2-year survival rate was $97.8 \%$, compared with $84.5 \%$, $66.1 \%$, and $45.2 \%$ for the low-, medium-, and high-risk groups, respectively.

Next, we analyzed the JCARE-CARD as a validation cohort. The Kaplan-Meier curves were similar to the derivation model (log-rank $\mathrm{P}<0.0001)$ (Figure 3). In the JCARE-CARD, for the extremely low-risk group, the 2-year survival was $95.4 \%$, compared with $90.2 \%, 75.0 \%$, and $55.6 \%$ for the low-, medium-, and high-risk groups, respectively.

\section{Discussion}

The $\mathrm{A}_{2} \mathrm{~B}$ score was derived using the NARA-HF study ${ }^{\mathbf{7 , 8}}$ and validated using the JCARE-CARD. ${ }^{10,11}$ These studies, unlike randomized, controlled trials, register all patients with ADHF and represent a more realistic model of the actual clinical population. In this population, the ROC for predicting 2-year survival was high $(95 \% \mathrm{CI}$ : $0.68-0.76)$ 
despite using only 3 independent predictors. $\mathrm{A}_{2} \mathrm{~B}$ score can be calculated immediately in the patient's presence, such as at the bedside or in the outpatient department, which is difficult with other risk scores. Thus, the $\mathrm{A}_{2} \mathrm{~B}$ score is an easy-to-use tool to estimate survival risk in patients with ADHF at discharge.

The present study used 3 factors that were independent predictors for ADHF mortality in this study. Age, $\mathrm{Hb}$, and plasma BNP at discharge have been previously reported as strong prognostic factors in ADHF.13-21 In this study, the cut-offs for each factor, obtained from the ROC curve, were 76 years for age, $11.7 \mathrm{~g} / \mathrm{dL}$ for $\mathrm{Hb}$, and $230 \mathrm{pg} / \mathrm{mL}$ for plasma BNP. These values were used as a reference for determining the risk score. Renal function was not an independent predictor in this study, consistent with the Seattle Heart Failure Model, ${ }^{2}$ but inconsistent with other models. ${ }^{22}$ In the present study adding eGFR had little effect on the ROC $(+0.001)$. Most previous HF risk models have not included plasma BNP, but plasma BNP level at discharge, unlike that at the acute phase, is recognized as one of the strongest prognostic factors. ${ }^{16-21}$

To compare with previous HF risk models, we applied the EMPHASIS-HF risk model to patients in the NARAHF study. ${ }^{7,8}$ In the EMPHASIS-HF trial itself, the median EMPHASIS-HF risk score was 5 (range, 0-11). ${ }^{6}$ In contrast, in the NARA-HF study, the median EMPHASIS-HF risk score was 7. One possible explanation for this difference is that the NARA-HF study registered all patients admitted with ADHF, and it appears that the NARA-HF study included patients with more severe disease. Next, we divided patients in the NARA-HF study into 3 groups according to EMPHASIS-HF risk group. The all-cause mortality rate for 2 years was $38.4 \%$ in the high-risk (7-12) category, $18.3 \%$ in the medium-risk (5-6) category, and $9.7 \%$ in the low-risk (0-4) category. This was similar to that in the EMPHASIS-HF study, ${ }^{6}$ and the 2 sets of prognoses were almost identical. Additionally, when we applied $\mathrm{A}_{2} \mathrm{~B}$ score to the JCARE-CARD, the average was lower than that in the NARA-HF study (2.6 \pm 1.6 vs. $3.1 \pm 1.6$, respectively; Supplementary Figure 1B). The overall prognoses, however, were very similar at the same score, and it was considered that the $\mathrm{A}_{2} \mathrm{~B}$ score could be used for patients with different backgrounds.

Because the NARA-HF study follows all patients for a prolonged time period as a dynamic cohort, we also evaluated long-term prognosis using $\mathrm{A}_{2} \mathrm{~B}$ score. As a result, even considering long-term prognosis, $\mathrm{A}_{2} \mathrm{~B}$ score was good for stratification of disease severity and was very useful for determining prognosis (Supplementary Figure 2A). Furthermore, we assessed $\mathrm{HF}$ hospitalization with the $\mathrm{A}_{2} \mathrm{~B}$ risk score. Of the 4 groups, the extremely low-risk (0) group had a lower rehospitalization rate than the other 3 groups (low risk, 1-2; medium risk, 3-4; and high risk, 5-6) in both NARA-HF (log-rank $\mathrm{P}=0.0046$ ) and JCARE-CARD (log-rank $\mathrm{P}<0.0001$; Supplementary Figure 2B). Although $\mathrm{A}_{2} \mathrm{~B}$ score stratification was not as clear as that using 2-year mortality, the risk score could be used to some degree in the prediction of HF hospitalization.

We were able to create a very simple risk score for use in patients with ADHF at discharge, which will be useful for therapeutic decision-making in the management of patients admitted with ADHF. For patients with an extremely low-risk $\mathrm{A}_{2} \mathrm{~B}$ score, a good prognosis can be expected by continuing treatment in compliance with the guidelines. In contrast, patients with a high-risk $\mathrm{A}_{2} \mathrm{~B}$ score represent those with end-stage $\mathrm{HF}$, and a therapeutic strategy including end-of-life care should be considered. The strongest point of this study is that these decisions can be easily made using $\mathrm{A}_{2} \mathrm{~B}$ score at the time of discharge or during outpatient management of patients with ADHF.

\section{Study Limitations}

The present study has the following limitations. First, this study was performed using Japan registries and involved only Japanese patients; therefore, Western populations were not assessed. Second, we could not include all registered patients because of data loss. The background of the included patients vs. that of all registered patients, however, were very similar (Table 1, Supplementary Table). Third, in this type of study, young patients who require an LV assist device or heart transplantation are rarely included, and it is unknown whether these data apply to such a limited group of patients.

\section{Conclusions}

The $\mathrm{A}_{2} \mathrm{~B}$ risk score is an easy-to-use estimate of survival risk in patients with ADHF at discharge. Physicians could use the $\mathrm{A}_{2} \mathrm{~B}$ score to make decisions about future management strategies on the basis of patient survival risk.

\section{Acknowledgments}

The authors would like to acknowledge Yoko Wada, Yuki Kamada, Rika Nagao, and Ikuyo Yoshida for their support in the data collection process.

\section{Sources of Funding}

This work was supported in part by Grants-in-Aid for Scientific Research (B) from the Ministry of Education, Culture, Sports, Science, and Technology of Japan.

\section{Disclosures}

The authors declare no conflicts of interest.

\section{References}

1. Lee DS, Austin PC, Rouleau JL, Liu PP, Naimark D, Tu JV. Predicting mortality among patients hospitalized for heart failure: Derivation and validation of a clinical model. JAMA 2003; 290: $2581-2587$.

2. Levy WC, Mozaffarian D, Linker DT, Sutradhar SC, Anker SD, Cropp AB, et al. The Seattle Heart Failure Model: Prediction of survival in heart failure. Circulation 2006; 113: 1424-1433.

3. Pocock SJ, Wang D, Pfeffer MA, Yusuf S, McMurray JJ, Swedberg KB, et al. Predictors of mortality and morbidity in patients with chronic heart failure. Eur Heart J 2006; 27: 65-75.

4. O'Connor CM, Whellan DJ, Wojdyla D, Leifer E, Clare RM, Ellis SJ, et al. Factors related to morbidity and mortality in patients with chronic heart failure with systolic dysfunction: The HF-ACTION predictive risk score model. Circ Heart Fail 2012; 5: $63-71$.

5. Pocock SJ, Ariti CA, McMurray JJ, Maggioni A, Køber L, Squire IB, et al. Predicting survival in heart failure: A risk score based on 39372 patients from 30 studies. Eur Heart J 2013; 34: $1404-1413$

6. Collier TJ, Pocock SJ, McMurray JJ, Zannad F, Krum H, van Veldhuisen DJ, et al. The impact of eplerenone at different levels of risk in patients with systolic heart failure and mild symptoms: Insight from a novel risk score for prognosis derived from the EMPHASIS-HF trial. Eur Heart J 2013; 34: 2823-2829.

7. Nakada $Y$, Kawakami R, Matsui M, Ueda T, Nakano T, Takitsume A, et al. Prognostic value of urinary neutrophil gelatinase-associated lipocalin on the first day of admission for adverse events in patients with acute decompensated heart failure. $J$ Am Heart Assoc 2017; 6: e004582.

8. Ueda T, Kawakami R, Nishida T, Onoue K, Soeda T, Okayama 
$\mathrm{S}$, et al. Left ventricular ejection fraction (EF) of 55\% as cutoff for late transition from heart failure (HF) with preserved $\mathrm{EF}$ to HF with mildly reduced EF. Circ $J$ 2015; 79: 2209-2215.

9. McKee PA, Castelli WP, McNamara PM, Kannel WB. The natural history of congestive heart failure: The Framingham study. N Engl J Med 1971; 285: 1441-1446.

10. Hamaguchi S, Kinugawa S, Tsuchihashi-Makaya M, Goto K, Goto D, Yokota T, et al. Spironolactone use at discharge was associated with improved survival in hospitalized patients with systolic heart failure. Am Heart J 2010; 160: 1156-1162.

11. Hamaguchi S, Kinugawa S, Tsuchihashi-Makaya M, Goto D, Yamada S, Yokoshiki H, et al. Loop diuretic use at discharge is associated with adverse outcomes in hospitalized patients with heart failure: A report from the Japanese Cardiac Registry of Heart Failure in Cardiology (JCARE-CARD). Circ J 2012; 76: $1920-1927$.

12. Matsuo S, Imai E, Horio M, Yasuda Y, Tomita K, Nitta K, et al. Revised equations for estimated GFR from serum creatinine in Japan. Am J Kidney Dis 2009; 53: 982-992.

13. Kajimoto K, Sato N, Takano T. Investigators of the Acute Decompensated Heart Failure Syndromes (ATTEND) registry: Association between anemia, clinical features and outcome in patients hospitalized for acute heart failure syndromes. Eur Heart J Acute Cardiovasc Care 2015; 4: 568-576.

14. Hamaguchi S, Tsuchihashi-Makaya M, Kinugawa S, Yokota T, Takeshita A, Yokoshiki H, et al. Anemia is an independent predictor of longterm adverse outcomes in patients hospitalized with heart failure in Japan: A report from the Japanese Cardiac Registry of Heart Failure in Cardiology (JCARE-CARD). Circ $J$ 2009; 73: $1901-1908$.

15. Yamauchi T, Sakata Y, Takada T, Nochioka K, Miura M, Tadaki S, et al. Prognostic impact of anemia in patients with chronic heart failure: With special reference to clinical background: Report from the CHART-2 Study. Circ J 2015; 79: 1984-1993.

16. Tsutamoto T, Wada A, Maeda K, Hisanaga T, Maeda Y, Fukai $\mathrm{D}$, et al. Attenuation of compensation of endogenous cardiac natriuretic peptide system in chronic heart failure: Prognostic role of plasma brain natriuretic peptide concentration in patients with chronic symptomatic left ventricular dysfunction. Circulation 1997; 96: 509-516.

17. Omland T, Persson A, Ng L, O’Brien R, Karlsson T, Herlitz J, et al. N-terminal pro-B-type natriuretic peptide and long-term mortality in acute coronary syndromes. Circulation 2002; 106: $2913-2918$.

18. Anand IS, Fisher LD, Chiang YT, Latini R, Masson S, Maggioni $\mathrm{AP}$, et al. Changes in brain natriuretic peptide and norepinephrine over time and mortality and morbidity in the Valsartan Heart Failure Trial (ValHeFT). Circulation 2003; 107: 1278-1283.

19. Suzuki S, Yoshimura M, Nakayama M, Mizuno Y, Harada E, Ito T, et al. Plasma level of B-type natriuretic peptide as a prognostic marker after acute myocardial infarction: A long-term follow-up analysis. Circulation 2004; 110: 1387-1391.

20. Price JF, Thomas AK, Grenier M, Eidem BW, O'Brian Smith E, Denfield SW, et al. B-type natriuretic peptide predicts adverse cardiovascular events in pediatric outpatients with chronic left ventricular systolic dysfunction. Circulation 2006; 114: $1063-$ 1069 .

21. Nishii $\mathrm{M}$, Inomata $\mathrm{T}$, Takehana $\mathrm{H}$, Naruke $\mathrm{T}$, Yanagisawa $\mathrm{T}$, Moriguchi M, et al. Prognostic utility of B-type natriuretic peptide assessment in stable low-risk outpatients with nonischemic cardiomyopathy after decompensated heart failure. $\mathrm{J} \mathrm{Am} \mathrm{Coll}$ Cardiol 2008; 51: 2329-2335.

22. Brophy JM, Dagenais GR, McSherry F, Williford W, Yusuf S A multivariate model for predicting mortality in patients with heart failure and systolic dysfunction. Am J Med 2004; 116: $300-304$.

\section{Supplementary Files}

Please find supplementary file(s); http://dx.doi.org/10.1253/circj.CJ-18-1116 